\title{
International Transmission of U.S. Real and Nominal Shocks
}

\author{
Dr. Bamadev Paudel \\ Department of Economics, Wayne State University \\ 656 W. Kirby, Room 2074, Detroit, MI 48202, USA
}

Tel: 1-248-703-2022 E-mail: bpaudel@wayne.edu

Received: April 29, 2011

Accepted: May 13, 2011

doi:10.5539/ijef.v3n3p50

\begin{abstract}
The real and nominal shocks in the U.S. are identified by using long-run implications of an open economy stochastic macroeconomic model, and the effects of these shocks are observed in real GDP, effective exchange rates, and the prices for the U.S. relative to each of six other G-7 countries. While Blanchard and Quah's long-run identification strategy is used to identify the shocks, short-run implication of the model are also exploited, as a prima facie evidence, by applying appropriate sign restrictions in the VAR estimation. Consistent with the model's predictions, a positive supply shock results in an increase in relative U.S. real GDP and a real depreciation of U.S. currency whereas nominal shocks in the U.S. lead to an increase in relative U.S. real GDP and relative U.S. prices. The application of short-run dynamics with proper sign restrictions into the VAR estimation produces exchange rate overshooting following the U.S. real shocks.
\end{abstract}

Keywords: Open Economy Macroeconomic Model, Structural Vector Autoregression, Short-run Dynamics

\section{Introduction}

This study examines the international transmission of U.S. real and nominal shocks on key macroeconomic variables of G-7 countries. We develop a theoretical rational expectation open economy macroeconomic model, and this mode's long-run implications are used to identify monetary and real shocks. While the identification technique as pioneered by Blanchard and Quah (1989) is applied to exploit long-run implications of the model, appropriate sign restrictions as implied by the model's short-run dynamics are also exploited (into the contemporaneous coefficient matrix of the VAR model) to account for the short-run implications of the model. The effects of identified shocks on output, exchange rates, and inflation are observed for U.S. relative to each of six other G-7 countries. The theoretical model draws primarily on the open economy macro model developed by Obstfeld (1985), while other ingredients of the model are also extracted from Mundell (1963), Fleming (1962) and Dornbusch (1976) (Note 1).

Transmission effects of shocks beyond international borders have been experimented in many theoretical and empirical works with varied range of predictions. The famous Mundell-Fleming model, for example, predicts that an increase in foreign interest rates as a result of monetary tightening abroad under fixed exchange rate regime would result in output reduction both at home and abroad. The increase in foreign interest rates as a result of expansionary government spending, however, would result in the expansion of foreign output but a reduction in domestic output. The effects of monetary and real shocks are rather different under flexible exchange rate system, leading to an expansion of domestic output and a contraction in foreign output after monetary contraction abroad but expansion in output both at home and abroad following expansion in government spending abroad. The models in New Open Economy Macroeconomics (NOEM) literature suggest different transmission effects than the Mundell-Fleming model (Note 2). A seminal work of NOEM, the Redux model, developed by Obstfeld and Rogoff (1995) predicts that the domestic monetary shocks raise the level of domestic output but shows an ambiguous effect on foreign output. An interesting result of this model is the lack of exchange rate overshooting, which is in contrary to the prediction of Dornbusch's (1976) dynamic Mundell-Fleming model. The exchange rate overshooting is, however, restored in Betts and Devereux's (2000a) model, which assumes incomplete exchange rate pass-through as opposed to complete exchange rate pass-through in Redux model (Note 3).

Within the premises of such diversified theoretical predictions, this study provides a fresh account of international transmission effects of U.S. real and nominal shocks in rest of G-7 countries by estimating a structural Vector Autoregression (SVAR) model. Earlier applications of VAR analysis in open economy macroeconomics are found in Clarida and Gali (1994) and Eichenbaum and Evans (1995). Clarida and Gali (1994) identify sources of real exchange rate fluctuations for post-Bretton Woods period for U.S., Japan, Germany, and Canada. The estimation of structural VAR in their study produces consistent results with the predictions of the Mundell-Fleming model showing that demand shocks lead to appreciation and monetary shocks lead to depreciation of the home currency. 
Eichenbaum and Evans (1995) also find the results similar to Clarida and Gali (1994). Kim (2001), on the other hand, estimates structural VAR to identify unidirectional effect of the US monetary policy shocks to the macroeconomic variables of G-7 countries and finds that the U.S. monetary expansion has a positive spillover effects on real GDP and industrial production of non-U.S. G-6 countries. Kim's results, however, do not seem to be consistent with the predictions of Mundell-Fleming and sticky price NOEM models.

Despite the prevalence of growing literatures that use VAR in explaining transmission effects of economic shocks, earlier studies were primarily designed for closed economy, and, if at all extended for open economy, the extensions were basically designed to explain exchange rate fluctuations. This study, however, provides a most recent contribution to explain the effects of shocks also on output and prices. As a prima facie attempt, we also notably include in our estimation the short-run implications of the model into the VAR estimation, which lacks in the earlier studies.

The empirical results show that there is a positive and persistent increase of U.S. real GDP relative to other countries' real GDP, and a depreciation of U.S. currency relative to other currencies following a supply shock. While the results with output and exchange rates are consistent with the predictions of the standard model, the response of relative price of home-produced goods to the price of foreign-produced goods after a supply shock does not confirm with the model's predictions. As with demand and monetary shocks, the response of relative real GDP is mostly in line with the model's predictions, whereas real and nominal effective exchange rates do not response as expected in the model following demand and monetary shocks. The variance decompositions show that relative real GDP is largely governed by supply shocks whereas demand shocks causes most of the variations in real/nominal effective exchange rates. Monetary shocks lead to a substantial variation in price differential between the countries. Most notable result of this study is the existence of exchange rate overshooting following a supply shock.

Rest of the paper is organized as follows: Section 3 describes the theoretical model. Section 3 provides an account of empirical strategy. Results are discussed in Section 4. Section 5 concludes.

\section{Model Framework}

Mondell-Fleming model is extensively-used model in policy-related research by central banks for over four decades, and the model derived here is similar to this model but extended as stochastic Mondell-Fleming model as pioneered by Obstfeld (1985). Following Clarida and Gali (1994), all variables used are U.S. relative to foreign country, which essentially makes this model as a two-country model. Foreign interest rates are set to zero without loss of generality. All variables except interest rates are in log.

The demand side of the economy is represented by the following IS equation

$$
y_{t}^{d}=\varphi\left(s_{t}-p_{t}\right)-\phi\left(i_{t}-E_{t}\left(p_{t+1}-p_{t}\right)\right)+d_{t}
$$

where $d_{t}$ is aggregate demand shock, and $i_{t}-E_{t}\left(p_{t+1}-p_{t}\right)$ is an ex ante real interest rate. Provided that $\varphi$ and $\phi$ are positive, real exchange rate $\left(s_{t}-p_{t}\right)$ and demand shocks have positive effects on aggregate demand whereas real interest rates have negative effect.

The LM equation is given by

$$
m_{t}^{s}-p_{t}=y_{t}^{d}-\kappa i_{t}
$$

where $\kappa>0$ and income elasticity of money demand is assumed to be unity.

Nominal rigidity is introduced in the following price-setting equation

$$
p_{t}=E_{t-1} \breve{p}_{t}+\theta\left(\breve{p}_{t}-E_{t-1} \breve{p}_{t}\right)
$$

where $\breve{p}$ is a shadow value of flexible price equilibrium. If $\theta=1$, prices are instantaneously perfectly flexible, and if $\theta=0$ they are completely fixed one period in advance. $0<\theta<1$ demonstrates intermediate degrees of price rigidity.

The following uncovered interest parity equation demonstrates the capital market equilibrium

$$
i_{t}=E_{t}\left(s_{t+1}-s_{t}\right)
$$

The shock processes are captured by the following three equations:

$$
y_{t}^{S}=y_{t-1}^{S}+\omega_{t}
$$




$$
\begin{gathered}
d_{t}=d_{t-1}+\mu_{t}-\tau \mu_{t-1} \\
m_{t}=m_{t-1}+\xi_{t}
\end{gathered}
$$

The supply shocks and monetary shocks are assumed to be pure random walks (equations (5) and (7)). The demand shocks also exhibit random walks; however, following Clarida and Gali (1994) a portion of the shocks are assumed to be reverting in the next period as demonstrated by the last term in equation (6). The introduction of this term in the demand shock process has implication for the application of Blanchard and Quah (1989) technique to estimate structural VAR model described in Section 3.

Flexible price solution $(\theta=1)($ Note 4$)$ :

Solution for real exchange rates:

Set $y_{t}^{s}=y_{t}^{d}$, assume real exchange rate $\breve{q}_{t}=s_{t}-p_{t}$, and substitute interest parity equation (4) into IS equation to get different equation for real exchange rates as

$\breve{q}_{t}=\frac{y_{t}^{S}-d_{t}}{\varphi+\phi}+\frac{\phi}{\varphi+\phi} E_{t} \breve{q}_{t+1}$

Using method of undetermined coefficients gives the solution for real exchange rates as

$$
\breve{q}_{t}=\frac{y_{t}^{S}-d_{t}}{\varphi}+\frac{\tau}{\varphi}\left(\frac{\phi}{\varphi+\phi}\right) \mu_{t}
$$

Equation (8) demonstrates that real exchange rate is affected only by real and demand shocks but not by monetary shocks.

Solution for Price:

Substitute (4) into (2) to get

$$
\breve{p}_{t}=m_{t}^{s}-y_{t}^{s}+\kappa E_{t}\left(s_{t+1}-s_{t}\right)
$$

Add $\breve{s}$ in both sides, add and subtract $\kappa E_{t} \breve{p}_{t+1}$ in the right hand side, apply definition of real exchange rates $\breve{q}_{t}=s_{t}-p_{t}, \quad$ and arrange the terms to get

$$
(1+\kappa) \breve{p}_{t}=m_{t}-y_{t}+\kappa\left(E_{t} \breve{q}_{t+1}-\breve{q}_{t}\right)+\kappa E_{t} \breve{p}_{t+1}
$$

From solution of real exchange rates in equation (8) and also using the shock processes, we obtain

$$
E_{t}\left(\breve{q}_{t+1}-\breve{q}_{t}\right)=\left(\frac{\kappa}{\varphi+\phi}\right) \mu_{t}
$$

Substitute this in equation (9) to obtain a stochastic difference equation for price as

$$
\breve{p}_{t}=\frac{m_{t}-y_{t}}{1+\kappa}+\frac{\tau \kappa}{(\varphi+\phi)(1+\kappa)} \mu_{t}+\frac{\kappa}{1+\kappa} E_{t} \breve{p}_{t+1}
$$

Using method of undetermined coefficients we obtain the solution for $\breve{p}_{t}$ as

$$
\breve{p}_{t}=m_{t}-y_{t}+\beta \mu_{t}
$$

where $\beta=\frac{\kappa \tau}{(1+\kappa)(\varphi+\phi)}$

Prices are affected by all three shocks in flexible price equilibrium as observed in equation (11).

Sticky price solution $(0<\theta<1)$ :

Solution for price:

Substitute price solution equation (11) into price setting equation (3) to get 


$$
p_{t}=\breve{p}_{t}-(1-\theta)\left(\xi_{t}-\omega_{t}+\beta \mu_{t}\right)
$$

where $\breve{p}_{t}$ is flexible price solution.

As can be seen in equation (12), the deviation of price from long-run equilibrium is negatively affected by demand and monetary shocks and positively by supply shocks.

Solution for real exchange rate:

Substitute (12) and (1) into (2) to obtain

$$
m_{t}-\breve{p}_{t}+(1-\theta)\left[\xi_{t}-\omega_{t}+\beta \mu_{t}\right]=d_{t}+\varphi q_{t}-(\phi+\phi)\left(E_{t} q_{t+1}-q_{t}\right)-\kappa E_{t}\left(p_{t+1}-p_{t}\right)
$$

Substitute (11) into (12) and get the expression for $E_{t}\left(p_{t+1}-p_{t}\right)$ as

$$
E_{t}\left(p_{t+1}-p_{t}\right)=-\beta \mu_{t}+(1-\theta)\left[\xi_{t}-\omega_{t}+\beta \mu_{t}\right]
$$

Substitute (14) and (10) into (11) to obtain stochastic difference equation for $q_{t}$ as

$$
(\varphi+\phi+\kappa) q_{t}=y_{t}-d_{t}+(1-\theta)(1+\kappa)\left(\xi_{t}-\omega_{t}\right)-\theta(1+\kappa) \beta \mu_{t}+(\phi+\kappa) E_{t} q_{t+1}
$$

Using method of undetermined coefficients gives the solution for $q_{t}$ as

$$
q_{t}=\frac{y_{t}-d_{t}}{\varphi}+\frac{\tau(\phi+\kappa)-\beta \varphi \theta(1+\kappa)}{\varphi(\varphi+\phi+\kappa)} d_{t}+\frac{(1-\theta)(1+\kappa)}{\varphi+\phi+\kappa}\left(\xi_{t}-\omega_{t}\right)
$$

Using (8) we can also have the solution for $q_{t}$ as

$$
q_{t}=\breve{q}_{t}+\frac{(1+\kappa)(1-\theta)}{\varphi+\phi+\kappa}\left[\xi_{t}-\omega_{t}+\beta \mu_{t}\right]
$$

For the solution of nominal exchange rates, $q_{t}$ and $p_{t}$ are substituted in the expression for nominal exchange rates $s_{t}$ $=q_{t}+p_{t}$ to obtain

$$
s_{t}=\breve{s}_{t}+(1-\varphi-\phi) \frac{(1-\theta)}{\varphi+\phi+\kappa}\left[\xi_{t}-\omega_{t}+\beta \mu_{t}\right]
$$

The solution for nominal exchange rates show that the deviation of real and nominal exchange rates from long-run equilibrium is positively affected by demand and monetary shocks and negatively by supply shocks, given $(\varphi-\phi)<0$. This shows that supply shocks can produce exchange rate overshooting, and this implication is tested empirically by estimating a VAR in Section 4 .

Solution for aggregate demand:

By using (4) we can write IS equation as

$$
\left.y_{t}^{d}=\varphi q_{t}-\phi E_{t}\left(\Delta q_{t+1}\right)\right)+d_{t}
$$

Forwarding one period ahead, using (10) and taking expectation for (15) to get

$$
E_{t}\left(\Delta q_{t+1}\right)=\frac{\tau}{\varphi+\phi} \mu_{t}-\frac{(1+\kappa)(1-\theta)}{\varphi+\phi+\kappa}\left[\xi_{t}-\omega_{t}+\beta \mu_{t}\right]
$$

Substituting (17) and (15) into (16) to obtain the solution for aggregate demand as

$$
y_{t}^{d}=y_{t}+\frac{(1+\kappa)(1-\theta)(\varphi+\phi)}{\varphi+\phi+\kappa}\left[\xi_{t}-\omega_{t}+\beta \mu_{t}\right]
$$

This equation exhibits that the deviation of real GDP from long-run equilibrium is positively affected by demand and monetary shocks and negatively by supply shocks, given $(\varphi-\phi)<0$.

In the short-run all variables are affected by all three shocks contemporaneously as shown by equations (12), (15), (16), and (18) but in the long-run the system becomes triangular as output is affected only by supply shocks (equation (5)), real exchange rates by supply and demand shocks (equation (8)), and price by all three demand, 
supply and monetary shocks (equation (11)). Both these long-run and short-run implications of the model are used in estimating structural VAR model described in the next section.

\section{Empirical Strategy}

\subsection{Structural VAR Model}

A two-country world is described by a following structural equation

$$
B y_{t}=\Gamma(L) y_{t}+e_{t}
$$

where $B$ is a contemporaneous coefficient matrix in structural equations, $y_{t}$ is $3 \times 1$ data vector which includes U.S. relative output, relative real/nominal effective exchange rates, and relative prices. $e_{t}$ is a $3 \times 1$ vector of structural shocks - aggregate supply shocks, aggregate demand shocks, and monetary shocks. $e_{t}$ are assumed to be serially uncorrelated with $\operatorname{Var}\left(e_{t}\right)=\Sigma$ as a diagonal matrix with unit variances of structural disturbances on the principal diagonal.

The VAR is estimated in the reduced-form equation as

$$
y_{t}=\Phi(L) y_{t}+u_{t}
$$

where $\Phi(L)=B^{-1} \Gamma(L), u_{t}=B^{-1} e_{t}$, and $\operatorname{Var}\left(u_{t}\right)=\Omega$.

Using the relationship $u_{t}=B^{-1} e_{t}$ and the assumption of $\Sigma=I$ gives $\Omega$ as

$$
\Omega=B^{-1} B^{-1^{\prime}}
$$

Reduced-from model, which downsizes the structural representation of the system, leads to identification problem. To recover the parameters of structural equations and the innovations thereto, we must impose restrictions on the structural system. There are two ways to restrict the system: first, the short-run restrictions employ both recursive (Sims (1980)), and non-recursive frameworks (Bernanke (1986), Sims (1986)) in the matrix B and the second, the long-run restrictions employ restriction on long-run multipliers. The identification strategy we apply here is long-run restrictions as suggested by Blanchard and Quah (1989). To apply this approach, the equations (19) and (20) are represented in the moving average form as

$$
y_{t}=\Theta(L) e_{t}
$$

From equations (23) and (24), the relationship between the structural and reduced-form parameters becomes

$$
\Theta(1)=\Psi(1) B^{-1}
$$

The matrix $\Psi(1)$ is obtained by using reduced-form estimated parameters $\hat{\Phi}^{\prime} s$ from equation (21), and $B^{-1}$ is estimated by using maximum likelihood estimation (Note 5). The long-run restrictions are applied in the matrix $\Theta(1)$ to recover $B^{-1}$. The restrictions come from long-run implication of the model described in Section III. That the model demonstrates that output is not affected by demand and monetary shocks and real exchange rate is not affected by monetary shocks makes the matrix of long-run multipliers $\Theta(1)$ a lower triangular matrix. This lower triangular condition helps identify matrix $B^{-1}$, and thereby $\Theta(L)$, and finally the impulse responses and variance decompositions.

In order to exploit the short-run implications of the model, we use the relationship $u_{t}=B^{-1} e_{t}$, in which appropriate sign restrictions are imposed on the matrix $B^{-1}$ so that the contemporaneous effects of the innovations are accordingly transmitted to the reduced-from disturbances and thereby to variables used in the model. The model's short-run dynamics implies that the supply shocks have negative adjustment process (that is, the difference between long-run equilibrium values and short-run sticky price values) for relative GDP and real/nominal effective exchange rates and positive for relative prices, whereas demand and monetary shocks have positive adjustment process for relative real GDP and relative real effective exchange rates but negative for real effective exchange rates (equations 12, 15, and 19). To incorporate this short-run characteristics of the model into the VAR estimation, we convert $B^{-1}$ matrix into a new matrix, say $C^{-1}$, such that $C^{-1}=M B^{-1} N$ where $m_{11}=1, m_{22}=1$ and $m_{33}=-1$, and $n_{11}=-1$, $n_{22}=1$ and $n_{33}=1$. With this specification, an important issue arises here and needs to be addressed. The results 
must be interpreted in growth rates. The shocks have effects only on the deviations of the variables from the long-run equilibrium in the short-run sticky price solution. As implied by the price setting rule, it is assumed that the long-run value is attained in the next period, thus the first difference can best be represented as short-run deviations of the variables from the long-run, which we do to obtain empirical results in VAR estimation.

\subsection{Data}

The international financial statistics (IFS) published by International Monetary Fund (IMF) is a major source of data for this study. As suggested by previous researchers, this is a rich source of data for open economy macro analysis, and the data in this source is available for large number of cross-sections ranging for many years. The study is confined only to G-7 countries (United States, United Kingdom, Canada, France, Germany, Italy, and Japan). This confinement is relevant in the sense that these countries have closer economic ties, and the shocks generated in any of these countries will have direct impact on the economies of other countries. For the estimation, we use quarterly data ranging from 1980Q1 to 2009Q2. The variables used are: real GDP, real effective exchange rates and GDP deflator. Since the quarterly flows of real GDP for U.S., CAN, JAP are not available in the IFS, they are obtained from OECD to generate consistent real GDP series for all countries. For exchange rates, we use effective exchange rates in place of ordinary exchange rates between two countries. Effective exchange rates are obtained by suitably weighing the exchange rate index for the country itself and the index of 20 other industrial countries. The justification for using such rates comes from the fact that our sample includes major industrial countries and such rates truly reflect the exchange rate behavior in these countries.

\section{Empirical Results}

This section summarizes the results obtained from estimating structural VAR model described in Section 3 . The variables used for this estimation are: log of relative real gross domestic product (RGDP), the log of relative real effective exchange rates (REER/NEER), and the log of relative GDP deflator (DEF), of the U.S. to foreign country. Since all these variables demonstrate unit roots (Table 1), the VAR uses their first differences. The first differences transform the variables used in the VAR specification as output growth rate differential, real effective exchange rates differential, and inflation differential. The lag length is determined by using AIC criterion, which supports for eight lags in the VAR specification.

Before explaining the impulse responses and variance decompositions, we first summarize the expected dynamics of the variables to supply, demand and monetary shocks as implied by our model (Table 2). The model described in the previous section predicts that the response of relative output in response to all three shocks is positive. The relative real effective exchange rates, on the other hand, depreciate in response to supply and monetary shocks but appreciate in response to demand shocks. The relative prices are observed positive in response to demand and monetary shocks but negative in response to supply shocks.

The impulse responses of relative U.S. real GDP, REER, and price levels to all shocks are reported in Figure 1. The impulse responses of relative real GDP to supply shocks is consistent with the predictions of the model. The impulse responses demonstrate that there is a positive response of home country's real GDP relative to foreign country's to supply shocks, which is valid for all country pairs, both in growth rates and levels of the variables. The one standard deviation of a supply shock, for example for the U.S./Canada pair, produces 2.4 percent increase in the U.S. real GDP relative to the Canadian real GDP. The relative real GDP persistently increases in response to supply shocks whereas it exhibits hump-shaped in response to demand and monetary shocks, which is consistent with the predictions of the prevailing standard macroeconomic models. For most of the country pairs, the effect of nominal shocks (demand and monetary shocks) continues to persist for nearly 16 quarters ahead and then die out.

The response of relative real effective exchange rates to supply shocks is also consistent with the model's predictions. The relative real effective exchange rates depreciate for all country pairs when there is a positive supply shock, a similar result as found in Stockman (1987) and Huizinga (1987). The supply shock effects on real exchange rates, on the other hand, continues to depreciate for all time horizons, which is attributable to our identification strategy in which supply shocks have long-run effects on the real exchange rates. In response to demand shocks, however, the relative real exchange rates do not appreciate as contrary to what has been suggested by the model. This can be justified with an argument that the demand shock generated in home country resulted in higher import demand leading to home country's currency depreciation. This is convincingly possible for the open economies such as those included in our sample. The effect of demand shocks on relative real effective exchange rates continues to persist as suggested by the flexible price solution of the model. The effect of monetary shocks to the real exchange rates is conformable to the model's prediction in most of the country pairs, resulting in a real depreciation of home currency in response to the monetary shocks. This result is consistent with the results also found in Mussa (1986). 
The monetary shocks, however, exert only short-run effects on the real effective exchange rates that last roughly 15 quarters in most of the country pairs.

The response of relative price of home-produced goods to the price of foreign-produced goods does not show the strong support in producing conformable results with the model's prediction. The implied negative effect of supply shocks to relative prices as predicted by the model is observed only for U.S./Canada pair. Likewise, the effect of demand shocks on relative prices leads to decrease in home country's relative price to foreign's, which also contradicts the predictions of the model. The effect of monetary shocks, however, is consistent with the model for all country pairs resulting in a rise in the U.S. relative price in response to monetary shocks in the U.S.. All shocks have persistent effect on relative price levels as suggested by our long-run characteristics of the model.

The most of the impulse responses for the U.S. against three countries France, Germany, and Italy appear somewhat problematic with regard to their conformability with the model's predictions. The justification of this behavior can be found in the time series properties of log of relative prices of the U.S. against the prices of these countries as shown by augmented Dicky-Fuller test statistics (Table 1). The reason can potentially be fact that these three countries are members of euro, and there was a regime change in these countries by participating in common euro currency beginning 1999, which certainly have effects on macroeconomic adjustment. In order to control the effect of this regime change, a dummy was introduced into the VAR estimation, and with this new specification the impulse responses did not change significantly but the effect of monetary shocks to explain relative real effective exchange rates come closer to the model's predictions (Fig. 2).

The variance decompositions in Table 3 demonstrate the proportion of movement of three variables included in the VAR specification as resulted from three different shocks. The results show that the movement in relative real GDP for all country pairs is mainly attributed to the supply shocks (results have been reported only for US/Canada pair and can be made available for other country pairs when requested. The results are similar for other country pairs also). In the first quarter of the relative U.S./Canada GDP, for instance, 96 percent variation of this output is explained by the supply shocks whereas only three percent and one percent variations are explained by demand and monetary shocks, respectively. The effects of demand and monetary shocks almost vanish at the end of the period, and therefore all movement in relative real GDP is explained entirely by supply shocks.

The movement in real effective exchange rates, on the other hand, is mainly governed by demand shocks. Except for the U.S./Germany country pair, more than 90 percent of variation in exchange rates in all country pairs is attributed to demand shocks. The monetary shocks do not play a major role to cause movement in relative real effective exchange rates.

Monetary shocks are dominant to explain relative price movement. More than 95 percent variation in relative price is attributed to monetary shocks for all country pairs except for U.S./Italy and U.S./UK country pairs. The demand shock, however, contributes for the most of the variation in later periods for the fluctuations of relative price level.

The impulse responses after applying sign restrictions from short-run dynamics of the model have been reported in Figure 3. The impulse responses demonstrate that output adjustment process is negative for all country pairs following supply shocks and vanishes after few quarters. The important thing to note here is that the impulse responses display the effects of supply shocks on the growth rate differential of real GDP between two countries, which suggests that after supply shocks in the domestic economy, the gap in growth rate differential between the U.S. and other countries narrows down. The demand and monetary shocks produces the similar convergent effect for real GDP but for most of the country pairs the impulse responses lies on the positive territory, which is justified by the short-run dynamics of the model.

For inflation rate differential, the supply shocks caused positive adjustment process whereas monetary and demand shocks generated negative adjustment process for most of the country pairs. This suggests that the inflation in the U.S. remains to be lower than the inflation in other countries after supply shocks in the U.S. economy, and the opposite happens when demand and monetary shocks hit the U.S. economy. The inflation rates in both countries, however, are equalized after few quarters as shown by the convergence of the impulse responses at zero level after some quarters.

The dynamics of relative real effective exchange rates is noteworthy here. The impulse responses suggest that in most of the country pairs, the appreciation rate in the U.S. from a supply shock is smaller than the appreciation rate of the foreign economy, whereas the depreciation rate of the U.S. currency is greater than the depreciation rate of the foreign currency, following demand and monetary shocks (only impulse responses for US/Canada pair have been shown). This observation is true also for nominal effective exchange rates. The gap remains to be larger at the beginning and comes to the convergence at the latter periods. Following the supply shocks, the nominal effective exchange rates temporarily falls below the long-run values as indicated by negative impulse responses for nominal 
effective exchange rates. This indicates that not only the monetary shocks but also real shocks are attributed to generate exchange rate overshooting.

In order to check the robustness of our results, we conduct two analyses: one estimates the models using winsorized data and another compares estimations of two sub-sample periods to observe whether the results differ significantly between these two sub-samples. Winsorized data produces similar results as the results shown above presumably due to the fact that there are no such outliers clearly observed in the data. For the second test, we break the entire sample in two sub-groups taking 2002:Q2 as a breaking point. This breaking point is supported by Qu and Perron (2007)'s test of structural changes in multivariate regressions. This breaking point deserves relevance also to the fact that the famously known dot-com bubble crashed around this time leading to the financial crisis and then to 2001 recession. We do not observe any significant difference in impulse responses for these two sub-sample periods which indicates that our results are robust.

\section{Conclusion}

We study the effects of the U.S. real and nominal shocks on key macroeconomic variables in G-7 countries by estimating structural VAR model. The impulse responses of U.S. real GDP relative to the rest of other countries to the supply shocks are consistent with the predictions of the model, resulting in a rise in U.S.'s real GDP compared to other countries' following the supply shocks in the U.S. The relative real GDP persistently increases in response to supply shocks whereas it exhibits hump-shape in response to demand and monetary shocks.

The responses of effective exchange rates to supply shocks are also consistent with the model's predictions. The relative real effective exchange rates depreciate in all country pairs when there is a positive supply shock in the U.S. The supply shock effects on real exchange rates remains persistent for a longer period of time. In response to demand shocks, however, the exchange rates do not appreciate as contrary to the model's prediction. The effect of monetary shocks to the real exchange rates is conformable to the model's prediction in most of the country pairs resulting in real depreciation of home currency in response to the monetary shocks in the U.S.

The responses of relative prices in the U.S. relative to the prices in other countries, on the other hand, do not show consistent prediction with the model. The expected negative effect of supply shocks to relative prices as predicted by the model is observed only for U.S./Canada pair. The effect of monetary shocks, however, are consistent with the model for all country pairs resulting in a rise in the U.S.'s relative prices in response to monetary shocks in the U.S..

The variance decompositions show that the movement in relative real GDP for all country pairs is mainly attributed to the supply shocks. The movement in real effective exchange rates, on the other hand, is mainly governed by demand shocks, whereas monetary shocks are dominant to explain relative price movement.

The exchange rates demonstrate a noteworthy behavior following the supply shocks, resulting in most of the country pairs a smaller appreciation rate in the U.S. than the appreciation rate in the foreign economy at the beginning and this effect dyes out after few quarters. This suggest that not only monetary and demand shocks cause exchange rate overshooting but supply shocks are also attributable for exchange rate overshooting.

While this study provides fresh account of explaining transmission effects of U.S. real and nominal shocks beyond international borders, the study is not free of shortcomings. The effects of U.S. shocks on international macroeconomic variables through terms trade and interest rate differentials have been have been ignored in this study. By addressing this issue, a realistic transmission mechanism of the effects of shocks from one country to other countries is expected.

\section{References}

Bernanke, B. (1986). Alternative Explanations of the Money-Income Correlation, Carnegie-Rochester Series on Public Policy, 25, pg. 49-99, doi:10.1016/0167-2231(86)90037-0, http://dx.doi.org/10.1016/0167-2231(86)90037-0

Betts, C., and Devereux, M. (2000a). Exchange Rate Dynamics in a Model of Pricing-to-market, Journal of International Economics, 50, pp. 215-244, doi:10.1016/S0022-1996(98)00036-1, http://dx.doi.org/10.1016/S0022-1996(98)00036-1

Blanchard, O. and Quah D. (1989). The Dynamic Effects of Aggregate Demand and Supply Disturbances, American Economic Review, 79, pp. 655-673.

Clarida, R., and Gali, J. (1994). Sources of Real Exchange Rate Fluctuations: How Important are Nominal Shocks? National Bureau of Economic Research (NBER) Working Paper Series, No. 4658.

Clarida, R., Galí, J., and Gertler, M. (2002). A Simple Framework for International Monetary Policy Analysis, Journal of Monetary Economics, 49, pp. 879-904, doi:10.1016/S0304-3932(02)00128-9, http://dx.doi.org/10.1016/S0304-3932(02)00128-9 
Corsetti, G., and Pesenti, P. (2005). International Dimensions of Optimal Monetary Policy, Journal of Monetary Economics, 52, pp. 281-305, doi:10.1016/j.jmoneco.2004.06.002, http://dx.doi.org/10.1016/j.jmoneco.2004.06.002

Corsetti, G., and Pesenti, P. (2007). The Simple Geometry of Transmission and Stabilization in Closed and Open Economies, NBER International Seminar on Macroeconomics 2007.

Dornbusch, R. (1976). Expectations and Exchange Rate Dynamics, Journal of Political Economy, 84, pp. 1161-76, doi:10.1086/260506, http://dx.doi.org/10.1086/260506

Eichenbaum M. and Evans C. (1995). Some Empirical Evidence on the Effects of Shocks to Monetary Policy on Exchange Rates, Quarterly Journal of Economics, 110, pp. 975-1009, doi:10.2307/2946646, http://dx.doi.org/10.2307/2946646

Fleming M.J. (1962). Domestic Financial Policies under Fixed and under Floating Exchange Rates, International Monetary Fund Staff Papers, 9, pp. 369-79, doi:10.2307/3866091, http://dx.doi.org/10.2307/3866091

Flood, R. (1981). Explanations of Exchange Rate Volatility and Other Empirical Regularities in Some Popular Models of the Foreign Exchange Market, Carnegie-Rochester Conference Series on Public Policy, 15.

Hamilton, J.D. (1995). Time Series Analysis, Princeton University Press, (Chapter 5).

Huizinga, J.(1987). An Empirical Investigation of the Long Run Behavior of Real Exchange Rates, Carnegie-Rochester Conference Series on Public Policy, 27, pp. 149-215, doi:10.1016/0167-2231(87)90007-8, http://dx.doi.org/10.1016/0167-2231(87)90007-8

Kim, S. (2001). International Transmission of US Monetary Policy Shocks: Evidence from VAR's, Journal of Monetary Economics, 48, pp. 339-372, doi:10.1016/S0304-3932(01)00080-0, http://dx.doi.org/10.1016/S0304-3932(01)00080-0

Lane, P.R. (2001). The New Open Economy Macroeconomics: A Survey, Journal of International Economics, 54, pp. 235-266, doi:10.1016/S0022-1996(00)00073-8, http://dx.doi.org/10.1016/S0022-1996(00)00073-8

Mundell R. A. (1963). Capital Mobility and Stabilization Policy under Fixed and Flexible Exchange Rates, Canadian Journal of Economics and Political Science, 29, pp. 475-485, doi:10.2307/139336, http://dx.doi.org/10.2307/139336

Mussa, M. (1982). A Model of Exchange Rate Dynamics, Journal of Political Economy, 90, pp. 74-104, doi:10.1086/261040, http://dx.doi.org/10.1086/261040

Mussa, M. (1986). Nominal Exchange Rate Regimes and the Behavior of Real Exchange Rates: Evidence and Implications, Carnegie-Rochester Conference Series on Public Policy, 26.

Obstfeld, M. (1985). Floating Exchange Rates: Experience and Prospects, Brookings Papers on Economic Activity 2, pp. 369-450, doi:10.2307/2534443, http://dx.doi.org/10.2307/2534443

Obstfeld, M., and Rogoff, K. (1995). Exchange Rate Dynamics Redux, Journal of Political Economy, 103, pp. 624-660, doi:10.1086/261997, http://dx.doi.org/10.1086/261997

Qu Z. and Perron, P. (2007). Estimating and Testing Structural Changes in Multivariate Regressions, Econometrica, 75 (2), pp. 459-502, doi:10.1111/j.1468-0262.2006.00754.x. http://dx.doi.org/10.1111/j.1468-0262.2006.00754.x

Sims C. (1980). Macroeconomics and Reality, Econometrica, 48, pp. 1-49, doi:10.2307/1912017, http://dx.doi.org/10.2307/1912017

Sims C. (1986). Are Forecasting Models Usable for Policy Analysis?, Federal Reserve Bank of Minneapolis Quarterly Review, pp. 3-16.

Stockman, A. (1987). The Equilibrium Approach to Exchange Rates, Federal Reserve Bank of Richmond Economic Review.

Woodford, M. (2007). Globalization and Monetary Control, National Bureau of Economic Research (NBER) Working Paper Series, No. 13329.

\section{Notes}

Note 1. For introducing nominal rigidity, we rely on a very simple price setting equation as pioneered by Flood (1981) and Mussa (1982), in which price adjustment is completed within one period.

Note 2. A detailed survey on the evolution and foundation of NOEM is found in Lane (2001). Imperfect competition, be it in product and/or factor markets, in general equilibrium setup is a key ingredient of the models in NOEM. These models aim to overcome the limitations of Mundell-Fleming model and emphasize international dimension of 
optimal monetary policy and desirability of international monetary policy cooperation. A far from complete list for further references includes Clarida, Gali, and Gertler (2002), Corsetti and Pesenti (2005), and Woodford (2007).

Note 3. A comprehensive analysis of transmission of shocks in incomplete exchange rate pass-through is found in Corsetti and Pesenti (2007). The authors provide a detailed analysis of shock transmission process in three different incomplete exchange rate pass-through regimes: local currency pricing (LCP), producer currency pricing (PCP), and dollar pricing (DP). The transmission effects are different for these three regimes.

Note 4. The flexible price solution is, in fact, a hypothetical solution, because we cannot characterize steady state in stochastic environment as economy is constantly hit by shocks. We, therefore, prefer to call this solution as shadow flexible price solution.

Note 5. To obtain $\Psi(1)$, the equation (20) is first represented in state-space form for Wold representation where the reduced-form estimated parameters $\hat{\Phi}^{\prime} s$ from equation (21) are used which provides us a $3 \times 3$ matrix $\Psi(1)$. The details on how to estimate $\Psi(1)$ is in gauss codes, which can be made available upon request. Unlike in Clarida and Gali (1994), we estimate $B^{-1}$ by using maximum likelihood estimation (likelihood function from Hamilton (1995), pp. 295).

Table 1. Unit Root Tests ${ }^{\#}$

\begin{tabular}{|c|c|c|c|c|c|c|c|c|c|c|c|c|}
\hline \multirow[b]{2}{*}{ Var. } & \multicolumn{2}{|c|}{ US/CAN } & \multicolumn{2}{|c|}{ US/FRA } & \multicolumn{2}{|c|}{ US/GER } & \multicolumn{2}{|c|}{ US/ITA } & \multicolumn{2}{|c|}{ US/JAP } & \multicolumn{2}{|c|}{ US/UK } \\
\hline & Level & $\begin{array}{l}\text { First } \\
\text { Diff. }\end{array}$ & Level & $\begin{array}{l}\text { First } \\
\text { Diff. }\end{array}$ & Level & $\begin{array}{l}\text { First } \\
\text { Diff. }\end{array}$ & Level & $\begin{array}{l}\text { First } \\
\text { Diff. }\end{array}$ & Level & $\begin{array}{l}\text { First } \\
\text { Diff. }\end{array}$ & Level & $\begin{array}{l}\text { First } \\
\text { Diff. }\end{array}$ \\
\hline $\operatorname{loggdp}$ & -0.7 & $-1.7 * *$ & -1.1 & -3.3 & -1.2 & -3.4 & -1.3 & -3.2 & -1.3 & -3.5 & -1.5 & -2.8 \\
\hline logneer & -0.3 & -2.9 & -1.3 & -3.0 & -1.1 & -3.2 & -1.1 & -3.0 & $-2.2 *$ & -3.4 & $-2.2 *$ & -3.4 \\
\hline logprice & -0.2 & -3.6 & $-2.2 *$ & $-2.0^{*}$ & $-2.1^{*}$ & $-2.1^{*}$ & -4.0 & -2.8 & -0.2 & -3.6 & -2.5 & $-1.6^{*}$ \\
\hline
\end{tabular}

Augmented Dicky-Fuller Statistics

*significant at 5\% level

** significant at $10 \%$ level

(a) significant at $10 \%$ level and 7 lags

\#Test for 8 lagged difference and without intercept

Table 2. Responses of relative RGDP, REER and DEF to Supply, Demand and Monetary Shocks as Suggested by the Model and Empirical Results

\begin{tabular}{|l|l|lr|l|l|l|l|l|}
\hline \multirow{2}{*}{ Shocks } & RGDP & \multicolumn{9}{l|l}{ REER/NEER } & DEF & \\
\cline { 2 - 9 } & Model & Actual & & Model & Actual & Model & Actual & \\
\hline Supply & Positive & Confirmed & & & Positive & Confirmed & Negative & $\begin{array}{l}\text { Contradicted (except for US/CAN and } \\
\text { US/FRA) }\end{array}$ \\
\hline Demand & Positive & $\begin{array}{l}\text { Confirmed } \\
\text { US/GER) }\end{array}$ & (except for & Negative & Contradicted & Positive & $\begin{array}{l}\text { Contradicted (except for US/CAN and } \\
\text { US/JAP) }\end{array}$ \\
\hline Monetary & Positive & $\begin{array}{l}\text { Confirmed } \\
\text { US/UK) }\end{array}$ & (except for & Positive & Contradicted & Positive & Confirmed \\
\hline
\end{tabular}

Table 3. Variance Decompositions

\begin{tabular}{|c|c|c|c|c|c|c|c|c|c|}
\hline \multirow[b]{2}{*}{ Qtrs. } & \multicolumn{3}{|c|}{ RGDP } & \multicolumn{3}{|c|}{ REER } & \multicolumn{3}{|c|}{ Price } \\
\hline & $\begin{array}{l}\text { Supply } \\
\text { Shock }\end{array}$ & $\begin{array}{l}\text { Demand } \\
\text { Shock }\end{array}$ & $\begin{array}{l}\text { Monetary } \\
\text { Shock }\end{array}$ & $\begin{array}{l}\text { Supply } \\
\text { Shock }\end{array}$ & $\begin{array}{l}\text { Demand } \\
\text { Shock }\end{array}$ & $\begin{array}{l}\text { Monetary } \\
\text { Shock }\end{array}$ & $\begin{array}{l}\text { Supply } \\
\text { Shock }\end{array}$ & $\begin{array}{c}\text { Demand } \\
\text { Shock }\end{array}$ & $\begin{array}{l}\text { Monetary } \\
\text { Shock }\end{array}$ \\
\hline 1 & 0.96 & 0.03 & 0.00 & 0.23 & 0.76 & 0.01 & 0.03 & 0.01 & 0.97 \\
\hline 10 & 0.92 & 0.07 & 0.02 & 0.30 & 0.69 & 0.01 & 0.02 & 0.25 & 0.72 \\
\hline 15 & 0.95 & 0.04 & 0.01 & 0.39 & 0.61 & 0.01 & 0.04 & 0.26 & 0.70 \\
\hline 20 & 0.97 & 0.03 & 0.01 & 0.46 & 0.54 & 0.01 & 0.05 & 0.25 & 0.70 \\
\hline 25 & 0.98 & 0.02 & 0.00 & 0.51 & 0.48 & 0.00 & 0.07 & 0.25 & 0.68 \\
\hline 30 & 0.98 & 0.01 & 0.00 & 0.55 & 0.45 & 0.00 & 0.08 & 0.26 & 0.66 \\
\hline 35 & 0.99 & 0.01 & 0.00 & 0.58 & 0.42 & 0.00 & 0.09 & 0.26 & 0.65 \\
\hline 40 & 0.99 & 0.01 & 0.00 & 0.60 & 0.39 & 0.00 & 0.10 & 0.26 & 0.64 \\
\hline
\end{tabular}

US/CAN Pair 

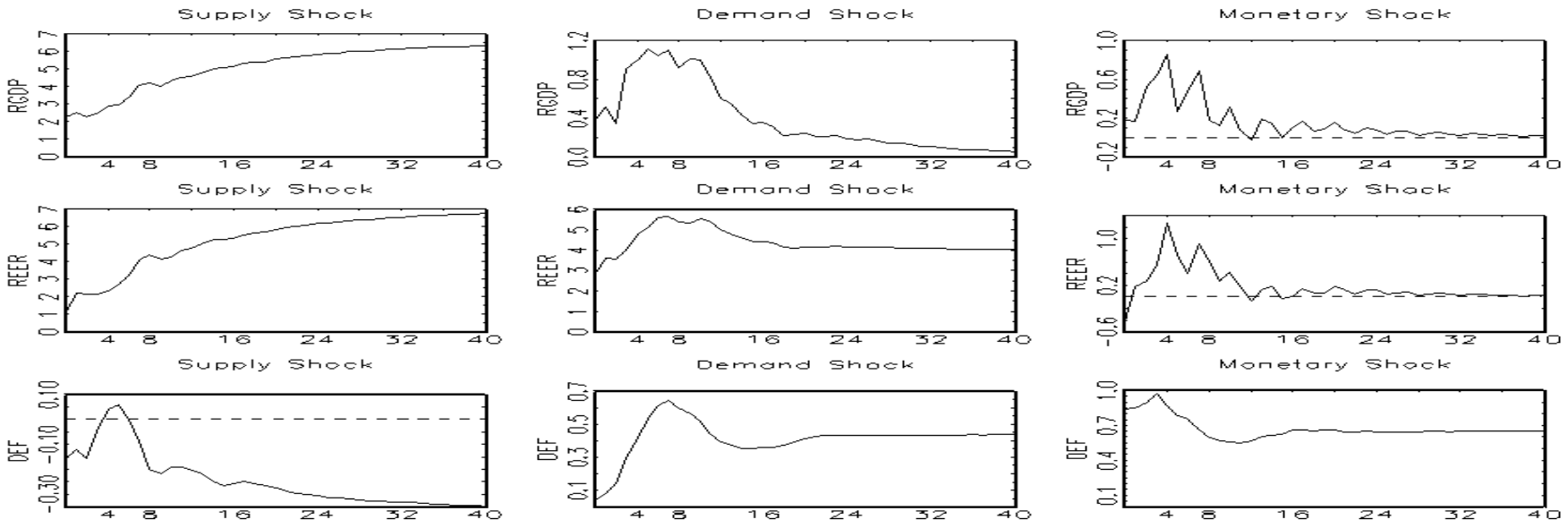

Figure 1(i). Impulse responses: US/CAN pair
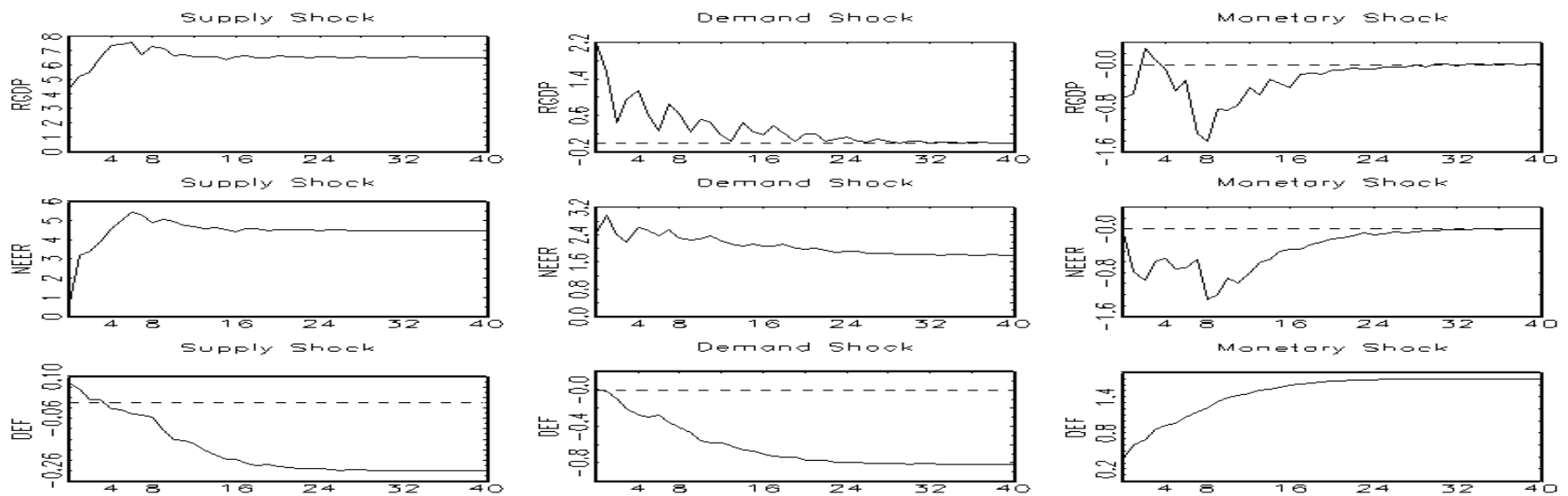

Figure 1(ii). Impulse responses: US/FRA pair
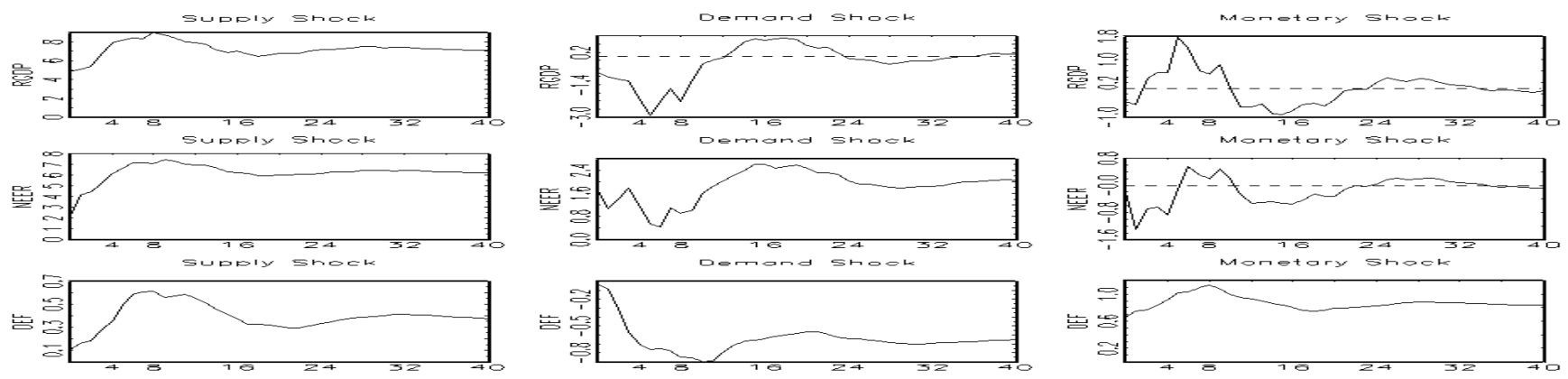

Figure 1(iii). Impulse responses: US/GER pair 

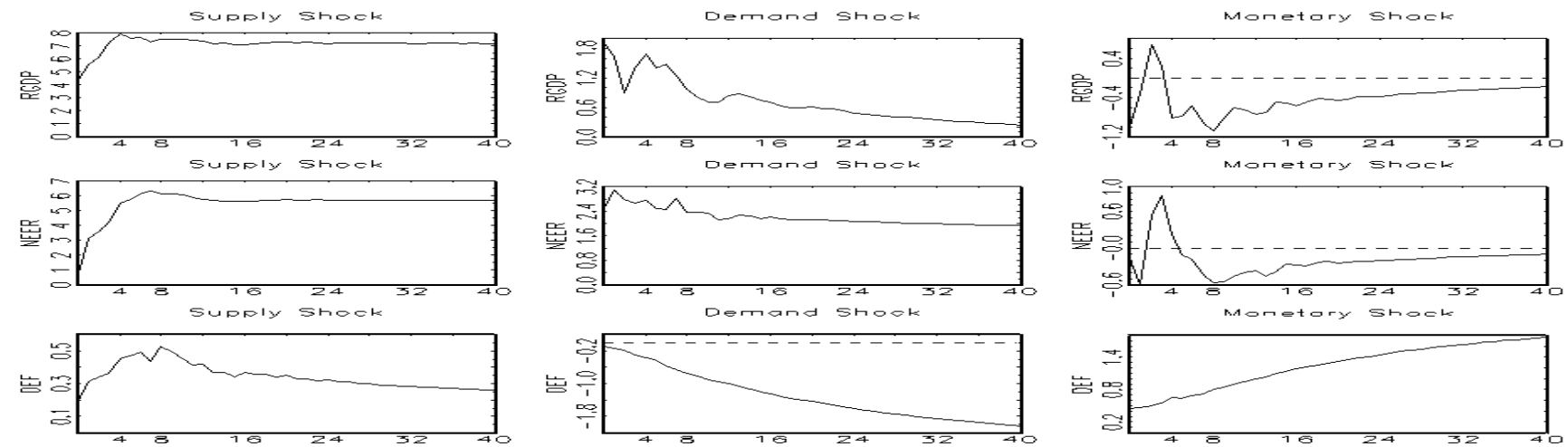

Figure 1(iv). Impulse responses: US/ITA pair
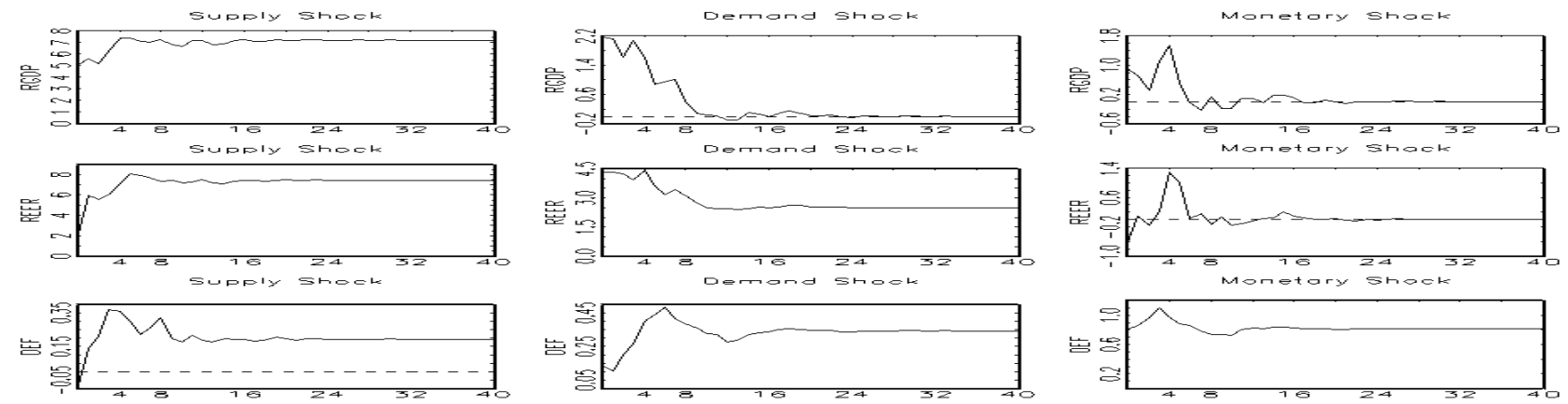

Figure 1(v). Impulse responses US/JAP pair
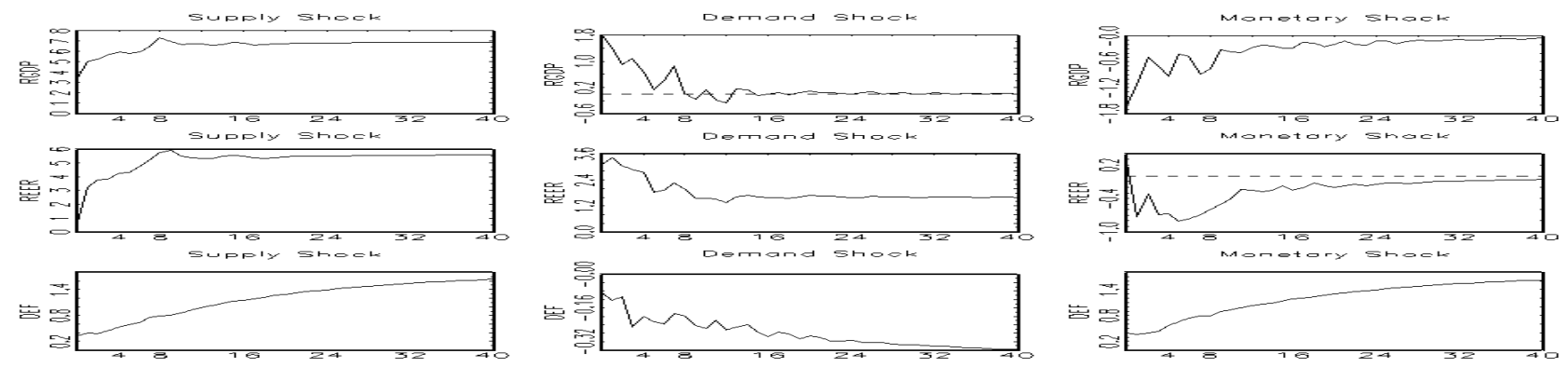

Figure 1(vi). Impulse responses: US/UK pair
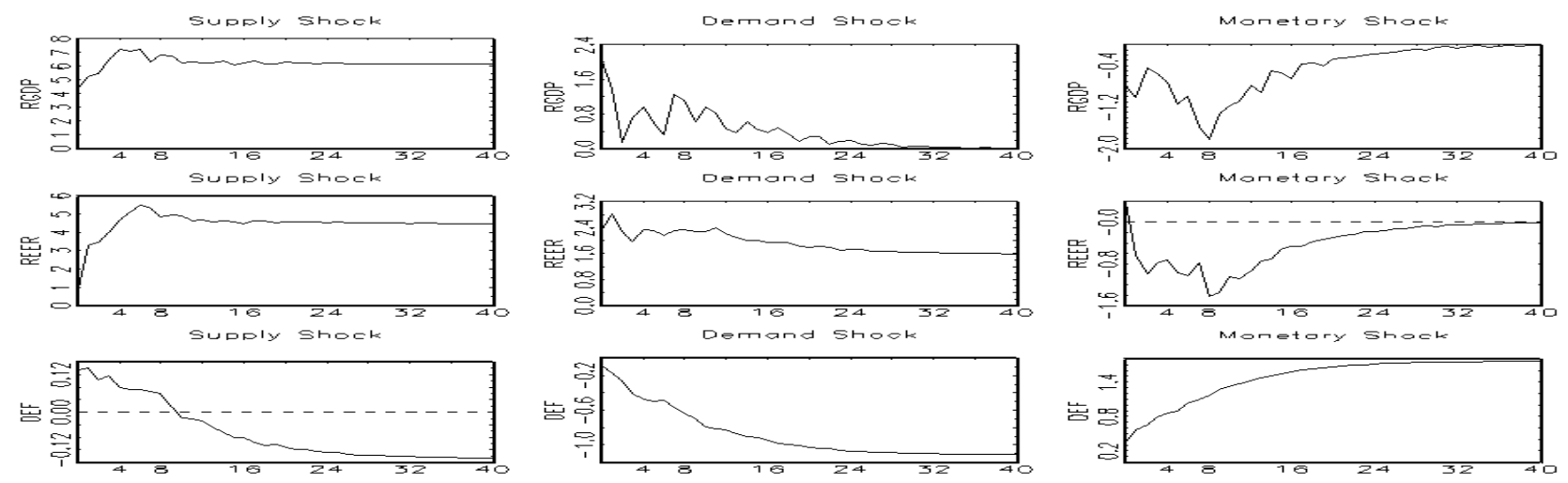

Figure 2 (i). Impulse responses: US/FRA pair (with regime change) 

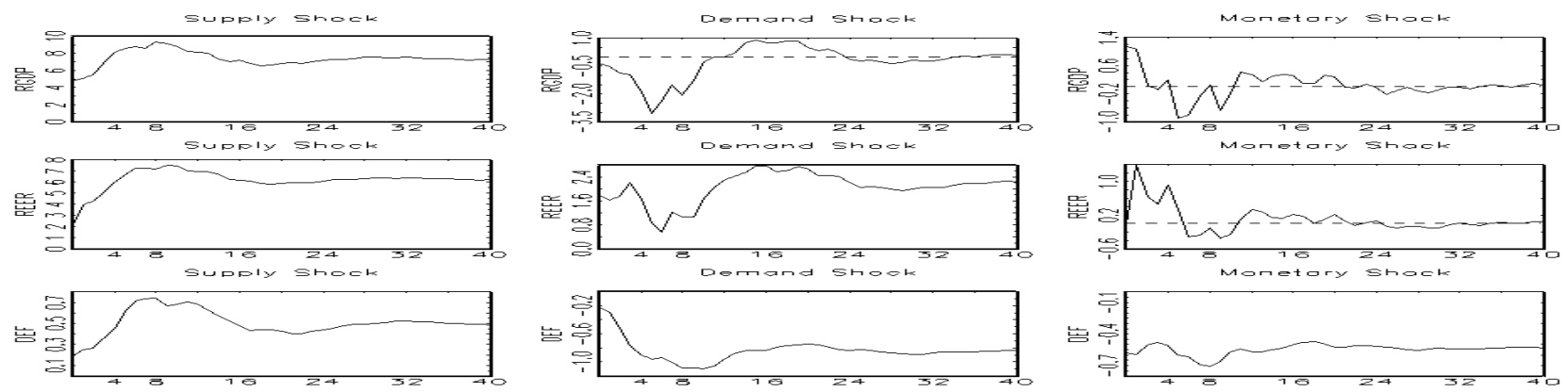

Figure 2 (ii). Impulse responses: US/GER pair (with regime change)
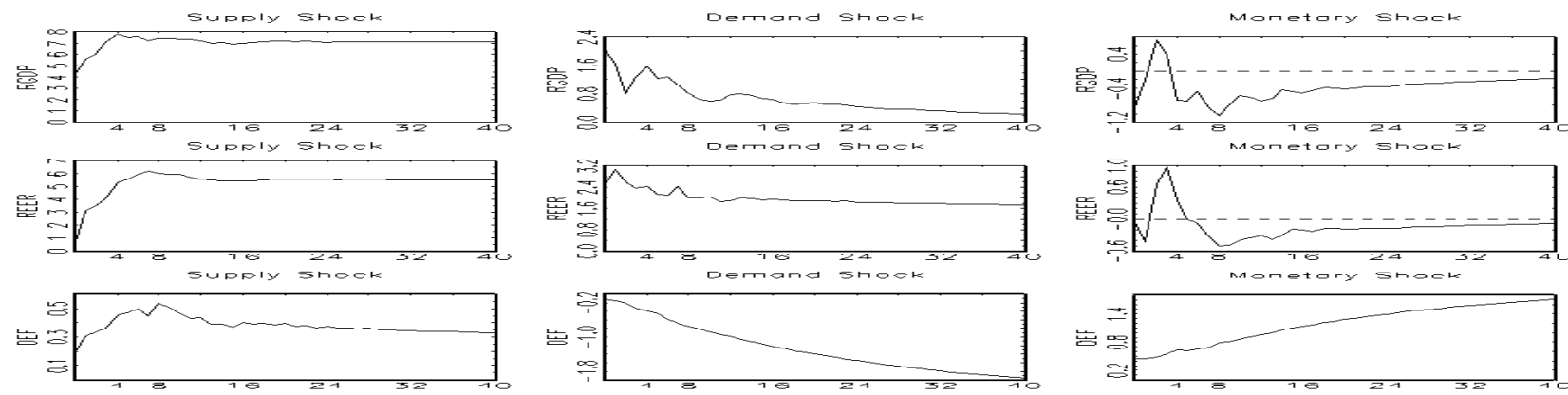

Figure 2 (iii). Impulse responses: US/ITA pair (with regime change)
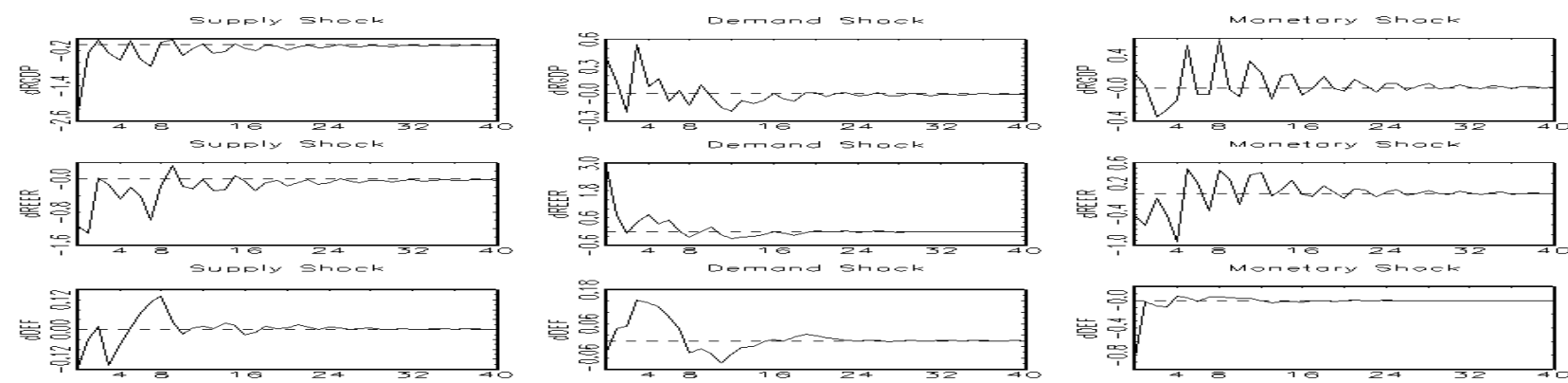

Figure 3. Impulse responses: US/CAN pair (with short-run sign restrictions) 